\title{
Delayed puberty in lambs chronically treated with oestradiol*
}

\author{
D. L. Foster, K. D. Ryan†, R. L. Goodman $\ddagger$, S. J. Legan§, F. J. Karsch and \\ S. M. Yellonף
}

Reproductive Endocrinology Program, Departments of Obstetrics and Gynecology, and Physiology and Division of Biological Sciences, The University of Michigan, Ann Arbor, Michigan 48109, U.S.A.

\begin{abstract}
Summary. Intact female lambs were chronically treated with low levels of oestradiol by Silastic implant from 20 weeks of age. Reproductive cycles were initiated in only $33 \%$ of these lambs ( 3 of 9 ) compared to $80 \%$ of untreated females ( 11 of 14 ) by 45 weeks when the study was terminated. Moreover, in the 3 oestradiol-treated lambs which began cycles, the age at first oestrus was delayed 3 weeks ( $37 \pm 1$ weeks of age vs $34 \pm 1$ weeks of age for untreated controls). Retardation of the pubertal process was not due to absence of the pubertal rise in circulating LH. At about 32 weeks of age, chronic oestradiol treatment was no longer able to suppress tonic $\mathrm{LH}$ secretion and serum $\mathrm{LH}$ increased in intact, oestradiol-treated lambs. These results indicate that a maturational decrease in responsiveness to oestradiol inhibition of tonic LH secretion can be demonstrated in the intact female, as in the ovariectomized female. However, chronic oestradiol suppression of prepubertal LH secretion also delays onset of reproductive cycles. This finding raises the possibility that low tonic LH secretion, presumably in the form of slow pulses, is necessary for development or maintenance of ovarian function before puberty. In the absence of LH during the last part of sexual maturation, the ability of the ovary to respond to the high frequency LH pulses during the pubertal gonadotrophin rise may be delayed.
\end{abstract}

\section{Introduction}

Central to the hypothesis for the transition into adulthood of the female sheep is that there is a decrease in responsiveness to oestradiol inhibition of tonic LH secretion (Foster, Yellon \& Olster, 1985). We have proposed that this allows concentrations of circulating LH to increase in order to drive follicular oestradiol production to levels that trigger the first LH surge. Evidence for the functional importance of the decrease in feedback response during sexual maturation in the sheep has been derived from observations relating to ovary-intact lambs and oestradiol-treated, ovariectomized lambs. In the intact lamb, an increase in tonic LH secretion precedes the initial LH surge, but because this is due to an increase in LH pulse frequency (Huffman \& Goodman, 1985), the rise

\footnotetext{
* Reprint requests to: Dr D. L. Foster, Reproductive Endocrinology Program, 300 North Ingalls, Room 1101, The University of Michigan, Ann Arbor, Michigan 48109, U.S.A.

$\dagger$ Present address: Department of Physiology, University of Pittsburgh School of Medicine, Pittsburgh, Pennsylvania 15261, U.S.A.

$\ddagger$ Present address: Department of Physiology and Biophysics, West Virginia University, Morgantown, West Virginia 26506, U.S.A.

§ Present address: Department of Physiology and Biophysics, University of Kentucky, Lexington, Kentucky 40506, U.S.A.

ๆ Present address: Department of Physiology, Loma Linda University, Loma Linda, California 92350, U.S.A.
} 
in LH baseline is difficult to demonstrate when blood samples are collected infrequently (Ryan \& Foster, 1978; Foster \& Ryan, 1979a). The oestradiol-treated, ovariectomized lamb has been used for studies of maturational changes in response to oestradiol negative feedback; a constant, low level of circulating oestradiol (Silastic implant) is more effective in suppressing tonic LH secretion before the age of first ovulation than afterward (Foster \& Ryan, 1979a; Foster, 1981; Foster \& Olster, 1985). In an attempt to examine relationships between developmental changes in oestradiol feedback inhibition of LH secretion ('neuroendocrine puberty') and onset of reproductive cycles ('ovarian puberty') within the same female, ovary-intact lambs were chronically treated with low levels of oestradiol.

\section{Materials and Methods}

Experiment 1. Female Suffolk lambs born 16 March ( \pm 2 days s.e.m.) were studied at the Reproductive Endocrinology Program Sheep Research Facility (Ann Arbor $42^{\circ} 18^{\prime} \mathrm{N}$ latitude). After weaning at an average age of 8 weeks, the 28 lambs had free access to pasture and were exposed continuously to mature vasectomized rams. Body weights were obtained twice monthly. The study was conducted under natural conditions. After 24 weeks of age (1 September), the lambs experienced artificial light for about 15 min each $4 \mathrm{~h}$ during the dark phase of the natural light cycle. This was because the females were maintained in the vicinity of a group of lambs being studied for another purpose that necessitated night-time blood sample collections. This light schedule had no discernible effect on the onset of reproductive cycles; the timing of puberty was similar to that (25-35 weeks of age) in other studies conducted entirely in natural photoperiod (Foster \& Ryan, 1979a; Foster, 1981; Foster, Ryan \& Papkoff, 1984).

Fourteen of the 28 lambs were treated chronically with low levels of oestradiol beginning at 20 weeks of age (early August). Oestradiol treatment was by s.c. placement in the axillary region of a small Silastic capsule (i.d. $0.33 \mathrm{~cm}$; o.d. $0.46 \mathrm{~cm}$; Dow-Corning, Midland, MI) containing a packed, 13-mm long column of the crystalline steroid. The capsules, designed to produce blood levels of 1-3 pg oestradiol/ml (Foster \& Ryan, 1979a; Foster, 1984), were incubated in tap water for $35 \mathrm{~h}$ (water changed at 1 and $24 \mathrm{~h}$ ) and then in ethanol for 20-60 min before insertion. Nine of the 14 oestradiol-treated lambs received no further treatment, and they were used as the primary experimental group to determine the temporal relationship between the decrease in oestradiol inhibition of $\mathrm{LH}$ secretion and onset of reproductive cycles within the same individual. The other 5 oestradioltreated lambs were used to assess the time of the pubertal decrease in response to oestradiol inhibitory feedback regulation of $\mathrm{LH}$ secretion in the absence of endogenous ovarian steroids; at the time of oestradiol implantation ( 20 weeks of age), they were bilaterally ovariectomized under pentobarbitone sodium anaesthesia $(400 \mathrm{mg} / \mathrm{ml})$ through a midventral incision. The remaining 14 lambs served as intact controls to determine the time of onset of reproductive cycles in the absence of any steroid treatment. Blood samples $(3-8 \mathrm{ml})$ were collected by jugular venepuncture and were stored at $4^{\circ} \mathrm{C}$ for $24 \mathrm{~h}$ before centrifugation. Serum was harvested and then stored frozen until assayed for $\mathrm{LH}$ and progesterone.

Determination of the onset of reproductive cycles was based primarily upon the initiation of oestrous behaviour and its subsequent occurrence at intervals of 15-17 days. Behavioural oestrus was ascertained by observation of females at least daily, as well as by recording paint marks on their hindquarters placed by the vasectomized males with painted briskets. The presence or absence of luteal function in late November was verified by measurement of serum progesterone in four blood samples obtained at intervals of 3 days. In oestradiol-treated lambs, serum LH was determined at 4-5-day intervals. Hormone measurements were discontinued at 38 weeks of age (4 December) when it was determined that puberty in oestradiol-treated, intact lambs was delayed. Records of oestrus were maintained until 1 February when the first breeding season ended in untreated lambs. 
Experiment 2. This study was conducted to determine whether oestradiol suppresses LH secretion before puberty by reducing $\mathrm{LH}$ pulse frequency or amplitude. Five Suffolk lambs born on 8 April ( \pm 1 day) were raised in a photoperiod sequence known to induce puberty and described in detail elsewhere (Yellon \& Foster, 1985), i.e. $9 \mathrm{~h}$ light:15 h dark (9L:15D) daily except for 17-22 weeks of age when exposed to $15 \mathrm{~L}: 9 \mathrm{D}$. Their rearing and other details of surgery were similar to those described in Exp. 1. They were ovariectomized at 10 weeks of age. At 12 weeks of age, blood samples $(3 \mathrm{ml})$ were collected by jugular venepuncture at 12-min intervals for $6 \mathrm{~h}(10: 00-16: 00 \mathrm{~h})$. A preincubated oestradiol-containing Silastic capsule was inserted s.c. after the last frequent blood sample, and the next day, beginning at $10: 00 \mathrm{~h}$, blood samples were again collected at 12-min intervals for $6 \mathrm{~h}$. LH concentrations were measured in the serum.

Assays. Concentrations of $\mathrm{LH}$ were measured in duplicate $200 \mu \mathrm{l}$ volumes of serum by modification (Hauger, Karsch \& Foster, 1977) of a radioimmunoassay described previously (Niswender, Reichert, Midgley \& Nalbandov, 1969); values below $20 \%$ binding of buffer control were reassayed in duplicate $50 \mu \mathrm{l}$ volumes. The limit of detection, $95 \%$ confidence limit of buffer controls, averaged $0.25 \mathrm{ng} / \mathrm{ml}$ for $200 \mu \mathrm{l}$ serum. Results are expressed in terms of NIH-LH-S12. Concentrations of progesterone were measured in duplicate $200 \mu \mathrm{l}$ volumes of serum by a modification (Foster, Lemons, Jaffe \& Niswender, 1975) of the radioimmunoassay described by Niswender (1973); the lower limit of detection was $0 \cdot 20 \mathrm{ng} / \mathrm{ml}$.

\section{Results}

\section{Experiment 1}

Treatment with exogenous oestradiol, beginning at 20 weeks of age, suppressed LH to undetectable concentrations in ovariectomized lambs (Fig. 1b) and in ovary-intact lambs (Fig. 1c). In both groups, circulating LH remained at low concentrations for several weeks. Thereafter, serum $\mathrm{LH}$ rose progressively, reflecting a decrease in response to oestradiol inhibitory feedback. In oestradioltreated, ovariectomized females, $\mathrm{LH}$ rose to, and was maintained at, concentrations of $>10 \mathrm{ng} / \mathrm{ml}$, whereas in oestradiol-treated intact lambs $\mathbf{L H}$ values generally remained at about half that concentration for several weeks. Moreover, at 38 weeks (last sample collected) LH decreased in these intact females.

In oestradiol-treated ovariectomized lambs, the decrease in response to steroid feedback inhibition exhibited a close temporal relationship to the initiation of puberty in untreated intact lambs. Serum $\mathrm{LH}$ rose above $1 \mathrm{ng} / \mathrm{ml}$ in oestradiol-treated ovariectomized lambs at $30 \pm 1$ weeks (Fig. 1b). First oestrus in intact lambs occurred at $34 \pm 1$ weeks of age (mean \pm s.e.m., 11 of 14 lambs; Fig. 1a), an estimated 1-3 weeks after first ovulation (31-33 weeks of age; see Foster \& Ryan, $1979 \mathrm{~b}$, for timing of 'silent' ovulation); the other 3 lambs did not exhibit oestrous behaviour by the end of the study (1 February). In oestradiol-treated intact lambs, the beginning of the LH rise was $32 \pm 1$ weeks (Fig. 1c; $\mathbf{L H}>1 \mathrm{ng} / \mathrm{ml}$ ). Only 3 of 9 oestradiol-treated intact lambs exhibited oestrus and luteal-phase levels of progesterone during the course of the study. For these females, the average age at first oestrus was $37 \pm 1$ weeks (Fig. 1c). The age ( $33 \pm 1$ weeks) when LH began to rise $(>1 \mathrm{ng} / \mathrm{ml})$ in oestradiol-treated intact lambs that did not begin reproductive cycles was similar to that $(31 \pm 1$ weeks) for those which did. Finally, the low percentage of oestradiol-treated lambs attaining puberty $(33 \%)$ compared to untreated lambs $(80 \%)$ was not due to differences in rate of growth; the average body weights of the two groups at 35 weeks of age, for example, were $39 \pm 2 \mathrm{~kg}(\mathrm{~N}=9)$ and $40 \pm 2 \mathrm{~kg}(\mathrm{~N}=14)$, respectively.

\section{Experiment 2}

In 12-week-old ovariectomized lambs, LH pulse frequency was high, the interpulse interval averaging $66 \pm 7$ min (mean \pm s.e.m., $N=5$ ) (Fig. 2). Oestradiol slowed pulse frequency within 

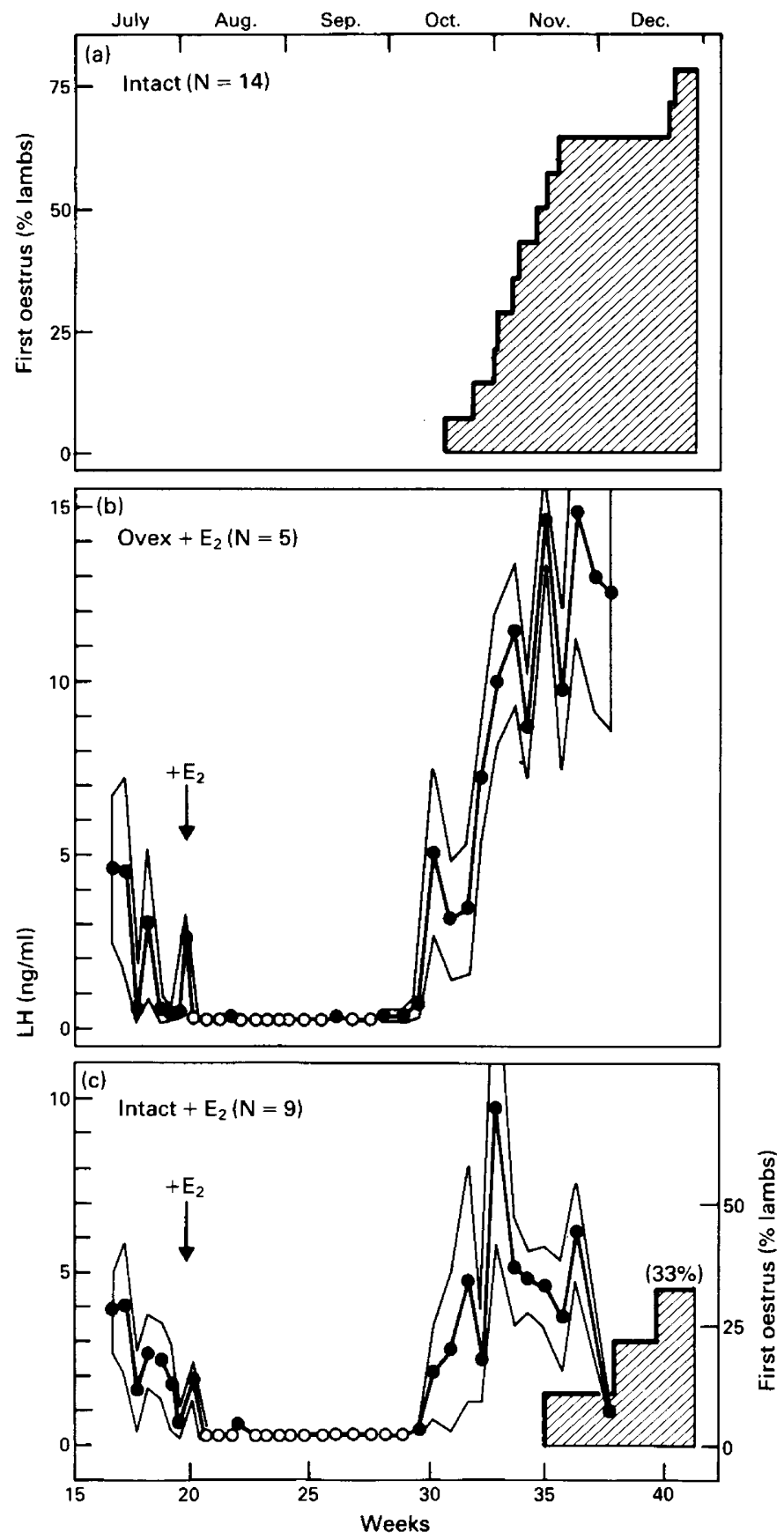

Fig. 1. (a) Onset of reproductive cycles (first oestrus, histogram) in untreated intact lambs. (b) Mean ( \pm s.e.m.) concentrations of circulating LH in ovariectomized (Ovex) lambs treated chronically with oestradiol ( $E_{2}$, Silastic capsule) from the time of ovariectomy (arrow). (c) Onset of reproductive cycles (histogram) and mean ( \pm s.e.m.) LH concentrations in intact lambs treated chronically with oestradiol $\left(E_{2}\right)$ beginning at 20 weeks of age (arrow). Undetectable values for serum $\mathrm{LH}(<0 \cdot 20 \mathrm{ng} / \mathrm{ml})$ are depicted by open circles. 


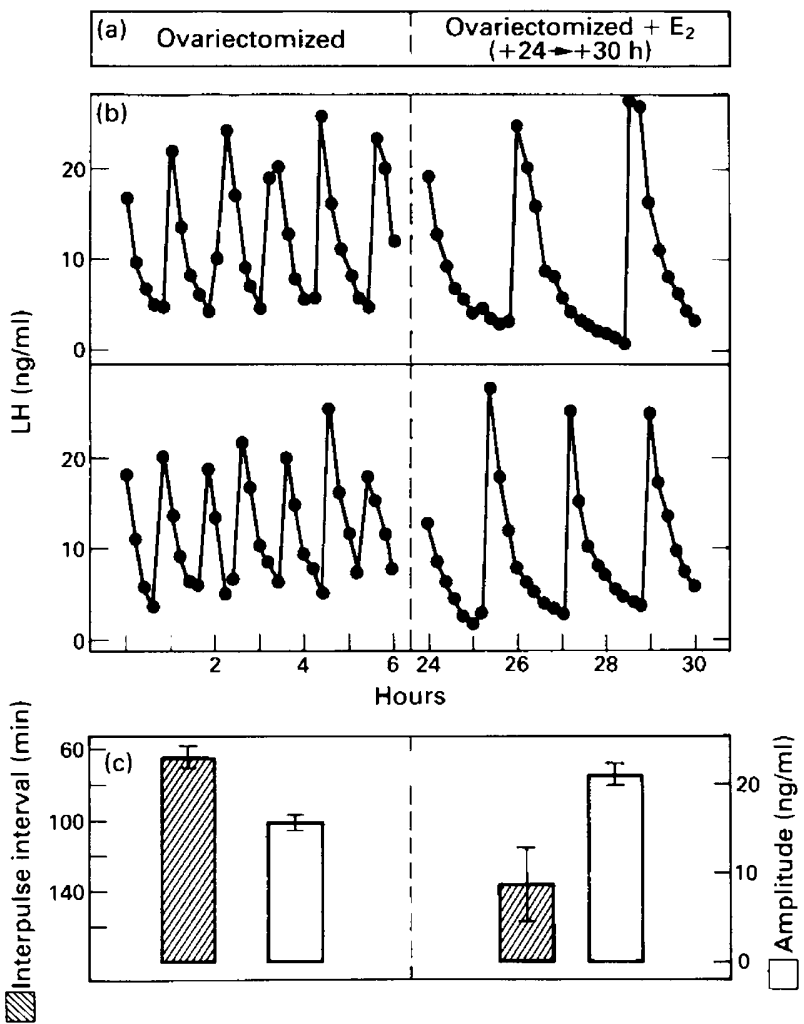

Fig. 2. Slowing effect of exogenous oestradiol on LH pulse frequency in the prepubertal, ovariectomized lamb. Experimental protocol (a) and patterns of circulating LH in two individual females before and 24-30 h after insertion of a small oestradiol implant (b). Mean \pm s.e.m. $(\mathrm{N}=5) \mathrm{LH}$ pulse frequency (interpulse interval) and amplitude $(\mathrm{ng} / \mathrm{ml}$, peak minus nadir) are presented (c).

$24 \mathrm{~h}$ (interpulse interval $137 \pm 20 \mathrm{~min}$ ) without reducing amplitude (Fig. 2). By $72 \mathrm{~h}$ few, if any, LH pulses can be detected in most females chronically treated with low dose oestradiol; therefore, LH pulses are rarely detected in oestradiol-treated, ovariectomized lambs during periods of frequent sampling before the age of puberty (L. E. Claypool \& D. L. Foster, unpublished).

\section{Discussion}

Central to our hypothesis for the neuroendocrine regulation of the transition into adulthood in the female sheep is that a decrease in response to oestradiol inhibition of $\mathrm{LH}$ secretion sets in motion a sequence of events that culminates in first ovulation (Foster et al., 1985, for review). The close temporal relationship between the increase in circulating $\mathrm{LH}$ in ovariectomized lambs chronically treated with oestradiol and the onset of reproductive cycles in ovary-intact lambs supports this view (Fig. 1). In the present study ovary-intact lambs were treated with low physiological quantities of oestradiol. As in the anoestrous ewe (Goodman, Bittman, Foster \& Karsch, 1982), exogenous oestradiol slows LH pulse frequency in the prepubertal female lamb (Fig. 2). We reasoned that elimination of the low-frequency, high-amplitude LH pulses typical of the immature female (Foster et al., 1975) would more easily reveal the pubertal onset of high frequency LH pulses (Huffman \& 
Goodman, 1985) characteristic of the follicular phase of the oestrous cycle (Foster et al., 1975; Baird, 1978; Karsch, Foster, Bittman \& Goodman, 1983). The latter pattern is postulated to occur during puberty, partly in response to the decrease in sensitivity to oestradiol negative feedback (Foster \& Olster, 1985). It can be inferred from the results of our studies that chronic oestradiol treatment effectively eliminated pulsatile $\mathrm{LH}$ secretion because of its ability to slow LH pulse frequency and because all LH values, even in infrequent blood sample collections, were undetectable in experimental lambs during the prepubertal period (before 30 weeks of age). However, the results also demonstrate that the oestradiol-treated, ovary-intact lamb cannot be used for studies of normal puberty because onset of reproductive cycles was markedly delayed.

The intact lamb treated chronically with gonadal steroids could better serve as a model for studies of the effects of prolonged hypogonadotrophism on gonadal function during sexual maturation. In the ram lamb, suppression of pulsatile LH secretion by exogenous steroid (progesterone) delays testicular development (Echternkamp \& Lunstra, 1984). Perhaps the low-frequency, high-amplitude LH pulses in the female lamb, which were eliminated by exogenous oestradiol for 9 weeks (20-29 weeks of age) during the prepubertal period, are necessary for ovarian development. On the other hand, perhaps the infrequent endogenous LH pulses that occur in the late prepubertal period (after 20 weeks of age) are only necessary to maintain an already developed ovary in a receptive state for the impending pubertal increase in LH pulse frequency that may occur anytime between 25 and 35 weeks of age (Foster \& Ryan, 1979a). This latter postulate is more likely. By 20 weeks the ovary of the lamb may be relatively mature because at this age, administration of low doses of purified LH will result in follicular development and ovulation (Foster et al., 1984). Thus, if a decrease in sensitivity of LH to the negative feedback of oestradiol were to occur at 20 weeks or after, the consequent rise in gonadotrophin should normally stimulate follicular growth and initiate reproductive cycles. It is clear from the current study, however, that low level oestradiol treatment delayed or eliminated the ability of the ovary to begin normal cyclic function in response to the increment in gonadotrophins that occurred during the pubertal period. The high LH concentrations were not sustained, and they appeared to decline after 35 weeks of age. Whether this reflected greater oestradiol production by the ovary, small amounts of progesterone from a luteinized follicle or even defective corpora lutea cannot be determined from the present study in which sexual receptivity was used as the main index of puberty.

Regardless of which of the foregoing explanations hold (ovarian development or maintenance), it will be necessary to determine whether the oestradiol-induced delay puberty stems from selective LH inhibition or to general hypogonadotrophism that involves reduced FSH concentrations. Circulating FSH was not measured in the present study because serum samples were discarded prematurely. It is possible that significant quantities of FSH may yet remain in the circulation if the effects of the exogenous steroid are the same as those in the anoestrous ewe, another physiological state characterized by hypersensitivity to steroid inhibitory feedback. In the ovariectomized ewe during the anoestrous season, similar blood levels of exogenous oestradiol to those used in the present study readily suppressed $\mathrm{LH}$ to undetectable concentrations, while at the same time circulating FSH was not depressed below levels typical of those found in the ovary-intact female (Legan \& Karsch, 1980). Finally, it may be argued that exposure to chronically elevated concentrations of exogenous oestradiol would directly alter ovarian development or function. The validity of this explanation remains to be determined in view of the fact that, in our model, the site of oestradiol administration (s.c.) was far removed from the ovary, and the ovary would therefore have been exposed to only very low circulating quantities of the exogenous steroid $(\sim \mathrm{l}-3 \mathrm{pg} / \mathrm{ml})$.

We thank Mr D. D. Doop for assistance in animal husbandry; Dr D. H. Olster for hormone assays; Dr G. D. Niswender, Colorado State University, and Dr L. E. Reichert, Jr, Albany Medical College of Union University, for reagents used in radioimmunoassays; Dr A. J. Zeleznik, University of Pittsburgh School of Medicine, for valuable advice in the writing of the manuscript; and Ms D. E. 
Belleba and Mr R. W. Jopling for preparation of the manuscript. This work was supported, in part, by grants from the Biomedical Research Council of The University of Michigan and the NIH (HD-05463, HD-08333, HD-12502, HD 18394 and HD-11311).

\section{References}

Baird, D.T. (1978) Pulsatile secretion of LH and ovarian estradiol during the follicular phase of the sheep estrous cycle. Biol. Reprod. 18, 359-364.

Echternkamp, S.E. \& Lunstra, D.D. (1984) Relationship between LH and testicular development in progesterone-implanted prepubertal ram lambs. $J$. Anim. Sci. 59, 441-453.

Foster, D.L. (1981) Mechanism for delay of first ovulation in lambs born in the wrong season (fall). Biol. Reprod. $25,85-92$.

Foster, D.L. (1984) Preovulatory gonadotropin surge system of prepubertal female sheep is exquisitely sensitive to the stimulatory feedback action of oestradiol. Endocrinology 115, 1186-1189.

Foster, D.L. \& Olster, D.H. (1985) Effect of restricted nutrition on puberty in the lamb: pattern of tonic luteinizing hormone ( $\mathrm{LH})$ secretion and competency of the LH surge system. Endocrinology 116, 375-381.

Foster, D.L. \& Ryan, K.D. (1979a) Endocrine mechanisms governing transition into adulthood: a marked decrease in inhibitory feedback action of estradiol on tonic secretion of luteinizing hormone in the lamb during puberty. Endocrinology 105, 896-904.

Foster, D.L. \& Ryan, K.D. (1979b) Mechanisms governing onset of ovarian cyclicity at puberty in the lamb. Annls Biol. anim. Biochim. Biophys. 19, 1369-1380.

Foster, D.L., Lemons, J.A., Jaffe, R.B. \& Niswender, G.D. (1975) Sequential patterns of circulating luteinizing hormone and follicle-stimulating hormone in female sheep from early postnatal life through the first estrous cycles. Endocrinology 97, 985-994.

Foster, D.L., Ryan, K.D. \& Papkoff, H. (1984) Hourly administration of luteinizing hormone induces ovulation in prepubertal female sheep. Endocrinology 115, 1179-1 185 .

Foster, D.L., Yellon, S.M. \& Olster, D.H. (1985) Internal and external determinants of the timing of puberty in the female. J. Reprod. Fert. 75, 327-344.
Goodman, R.L., Bittman, E.L., Foster, D.L. \& Karsch, F.J. (1982) Alterations in the control of luteinizing hormone pulse frequency underlie the seasonal variation in estradiol negative feedback in the ewe. Biol. Reprod. 27, 580-589.

Hauger, R.L., Karsch, F.J. \& Foster, D.L. (1977) A new concept for control of the estrous cycle of the ewe based on the temporal relationships between luteinizing hormone, estradiol and progesterone in peripheral serum and evidence that progesterone inhibits tonic LH secretion. Endocrinology 101, 807-817.

Huffman, L.J. \& Goodman, R.L. (1985) LH pulse patterns leading to puberty in the ewe lamb. Biol. Reprod. 32, Suppl. 1, 208, Abstr. 342.

Karsch, F.J., Foster, D.L., Bittman, E.L. \& Goodman, R.L. (1983) A role for estradiol in enhancing luteinizing hormone pulse frequency during the follicular phase of the estrous cycle of sheep. Endocrinology 113, 1333-1339.

Legan, S.J. \& Karsch, F.J. (1980) Photoperiodic control of seasonal breeding in ewes: modulation of the negative feedback action of estradiol. Biol. Reprod. 23, 1061-1068.

Niswender, G.D. (1973) Influence of the site of conjugation on the specificity of antibodies to progesterone. Steroids 22, 413-424.

Niswender, G.D., Reichert, L.E., Jr, Midgley, A.R., Jr \& Nalbandov, A.V. (1969) Radioimmunoassay for bovine and ovine luteinizing hormone. Endocrinology 84, 1166-1173.

Ryan, K.D. \& Foster, D.L. (1978) Necessity for a decrease in negative feedback of ovarian steroids on $\mathrm{LH}$ secretion at puberty in the lamb. Endocrinology 102, Suppl. 328, Abstr. 507.

Yellon, S.M. \& Foster, D.L. (1985) Alternate photoperiods time puberty in the female lamb. Endocrino$\log y$ 116, 2090-2097. 